\title{
ORIGENS DO CUSTO GERADO POR FALHAS INTERNAS NO SETOR PRODUTIVO: ESTUDO DE CASO EM UMA EMPRESA DO RAMO METAL MECÂNICO
}

\section{ORIGINS OF COST GENERATED BY INTERNAL FAILURES IN THE PRODUCTIVE SECTOR: A CASE STUDY IN A METAL MECHANICAL COMPANY}

\author{
Alex Eckert ${ }^{1}$; Marlei Salete Mecca ${ }^{2}$; Roberto Biasio ${ }^{3}$; Andressa Basso ${ }^{4}$ \\ ${ }^{1}$ Universidade de Caxias do Sul - UCS - RS - Brasil \\ aeckert@ucs.br \\ ${ }^{2}$ Universidade de Caxias do Sul - UCS - RS - Brasil \\ msmecca@ucs.br \\ ${ }^{3}$ Universidade de Caxias do Sul - UCS - RS - Brasil \\ rbiasio@ucs.br \\ ${ }^{4}$ Universidade de Caxias do Sul - UCS - RS - Brasil \\ dessinhabasso@hotmail.com
}

\begin{abstract}
Resumo
A busca pela identificação das origens das causas de falhas internas e a minimização de custos adicionais no setor produtivo está cada vez mais presente nas companhias. O estudo tem por objetivo levantar e identificar quais as principais origens do custo gerado por falhas internas na linha de produção de uma empresa do ramo metal mecânico de Caxias do Sul-RS. Para esse fim, utilizou-se o estudo de caso como metodologia de pesquisa. Com base em dados disponibilizados pela empresa, procedeu-se a tabulação e análise visando identificar a origem das perdas por falhas que a empresa teve durante o ano de 2012. Foi possível identificar que as falhas, como um todo, não representam, percentualmente, um custo muito alto para esta empresa, se comparado ao volume de faturamento da mesma. No entanto, o custo absoluto é significativo, o que justifica identificar suas origens e, com isso, proporcionar que sejam avaliadas ações para a sua redução. $O$ estudo também levantou que as falhas ocorrem de forma mais concentrada no setor de usinagem. Outra conclusão foi que também existe uma grande concentração quanto ao tipo de erro que causam as falhas, onde mais da metade de todo o custo de peças refugadas ocorre por três causas: falha causada por erro de usinagem, erro de operador e erro de projeto. Além da identificação do setor e das causas que geram o maior volume de custo, o estudo também levantou os principais motivos que acabam por dar origem às três principais causas.
\end{abstract}

Palavras-chave: Custos. Falhas internas. Erros internos. Usinagem. Ramo Metal Mecânico.

\section{Introdução}

O mercado atual está cada vez mais competitivo e, consequentemente, seus consumidores exigindo altos padrões de qualidade e preços reduzidos, recusando-se a pagar por produtos com 
deficiências. Diante dessa situação, as empresas se sentem pressionadas a estabelecer estratégias para que os produtos vendidos saiam da linha de produção com menor custo possível e sem nenhum defeito de fabricação, satisfazendo, assim, seus clientes.

Pode-se dizer que esses "defeitos de fabricação" são custos gerados por falhas durante o processo produtivo, sejam eles retrabalhos, refugos, desperdícios, entre outros. Esses custos oneram o custo da produção, o que faz com que as empresas acabem vendendo seus produtos por um preço maior e, logo, perdendo clientes para a concorrência. Segundo Maher (2001, p. 539), “os clientes compram o produto da companhia que cobra o menor preço; assim, ter custos baixos é fundamental para que a organização mantenha uma forte vantagem competitiva".

Para que isso ocorra, é necessário reduzir custos adicionais que não fazem parte do processo produtivo, como por exemplo, os custos gerados com perdas, falhas e retrabalho durante o processo de fabricação, além da ociosidade (ECKERT et al, 2013). Na visão de Maher (2001, p. 217), “a identificação de perdas na produção o mais cedo possível na cadeia de valor pode adicionar considerável valor às companhias".

Conseguindo essa minimização nos custos, com a redução de falhas internas, a empresa consegue repassar a seus clientes um produto de boa qualidade e com preço acessível para o consumo, podendo, assim, gerar maior lucro e a possibilidade do aumento de novos consumidores de seus produtos. Em outras palavras, as margens dos produtos estão cada vez menores, obrigando as empresas à redução de seus custos para manter sua rentabilidade.

Custos são gastos referentes a bens ou serviços utilizados na produção de outros bens ou serviços. Além dos custos que são necessários para a produção, também existem alguns custos que ocorrem sem agregar qualquer valor aos produtos.

Segundo Maher (2001, p. 206) "perdas na produção são produtos danificados, que não atendem às especificações ou que não podem ser processados adicionalmente ou vendidos aos clientes como um produto bom". Essas perdas, muitas vezes, se devem a falhas internas que ocorrem durante o processo produtivo. Isso acontece por não se fazer o procedimento correto ou também por problemas na máquina utilizada, gerando, assim, um retrabalho nos produtos, e, consequentemente, impactando em custos como tempo de máquinas e funcionários para reparar esses produtos. Devido a esse problema, é necessário mensurar o quanto custa tudo isso para a empresa. De acordo com Maher (2001, p. 206) "a mensuração do custo de perdas na produção e dos custos de sua redução permite que os administradores possam tomar decisões sobre o aperfeiçoamento da qualidade e reduções de custos".

Segundo Brandão et al (2010, p. 1) "a redução de refugos no ambiente industrial é fator de grande importância nas empresas modernas”. Esse fato justifica a escolha do tema da pesquisa, que tem como objetivo a identificar quais são as principais origens do custo gerado por falhas internas 
na linha de produção de uma empresa do ramo metal mecânico de Caxias do Sul - RS. Para atingir este objetivo, foi realizada uma pesquisa de natureza descritiva, através da análise de um estudo de caso único (YIN, 2005).

\section{Custos industriais}

\subsection{Contabilidade industrial: custos na indústria}

São vários os ramos em que a contabilidade se faz presente no contexto organizacional (ECKERT, 2013). Segundo Martins (2003), a contabilidade industrial é a área da contabilidade de custos que estuda os gastos gerados na fabricação de produtos na atividade industrial. Os custos industriais apurados dentro da empresa são somente da produção, ou seja, os gastos que são gerados durante o processo produtivo dos produtos. Já os gastos incorridos com o setor de administração são lançados como despesa. $\mathrm{O}$ custo industrial é tudo aquilo que se gasta para produzir um produto até o momento de este chegar ao balcão de vendas. Nestes custos entram hora homem, hora máquina, matéria-prima, energia, entre outros. Para Ferreira (2007, p. 18), "custo é o gasto relativo a um bem ou serviço utilizado na produção. São todos os gastos relativos à atividade de produzir”.

\subsection{Custos da qualidade}

Os custos da qualidade ocorrem quando o que foi projetado para certo produto deixa de atender os padrões de qualidade estabelecidos a ele, gerando retrabalho, desperdícios, perda de produtividade, entre outros. Em outras palavras, os custos da qualidade são todos os custos associados ao processo realizado para reparar um produto que, durante o processo de fabricação, saiu com algum defeito ou mesmo aqueles que foram deixados para refugos, que não têm mais conserto (PINTO e GOMES, 2011). Para Hansen e Mowen (2001, p. 514), "um produto defeituoso é aquele que não está em conformidade com as especificações".

“A qualidade, assim como a produtividade tem um efeito multiplicador” diz Alvez (1995, p. 8). O autor cita que um processo realizado de maneira incorreta no início da fabricação de um determinado produto fará com que todo o processo produtivo reflita negativamente nos custos. Quanto mais tempo levar para se descobrir o problema, mais custos serão gerados. Mesmo que este problema seja descoberto no início de seu processo, estes custos já não serão os mesmos de quando os produtos forem produzidos sem nenhum defeito. Tais custos não deveriam existir caso os processos fossem feitos de maneira correta e os produtos fabricados de forma eficaz e eficiente, ressaltam Ferreira e Medeiros (2007).

Nessas condições, os custos da qualidade são divididos em dois grupos: os custos de controle, que se subdividem em custo de prevenção e custo de avaliação; os custos de falhas no controle, que se subdividem em custos de falhas internas e custos de falhas externas. 


\subsection{Custos de controle}

Os custos de controles são aqueles incorridos em produtos que podem ter baixa qualidade ou estar em desacordo com as especificações feitas a ele, diz Sá (2003). Esses custos são fundamentais para que o produto saia perfeito da linha de produção. Os custos de controle são divididos em custo de prevenção e custo de avaliação.

"Os custos de prevenção incorrem para assegurar que as empresas produzam produtos, de acordo com os padrões de qualidade previamente estabelecida por elas", afirmam Pinto e Gomes (2010, p.6). Segundo Lins (2001), os custos de prevenção vêm dos processos realizados para fins de redução dos custos de falhas ou avaliação. $\mathrm{O}$ autor ainda cita algumas atividades que se enquadram nesse custo:

a) planejamento para a qualidade;

b) critérios e especificações;

c) análise de capacidade de processos;

d) manutenção preventiva;

e) treinamento;

f) qualificação de sistemas da qualidade.

Já em relação aos custos de avaliação, Pinto e Gomes (2010, p. 6) afirmam que "Os custos de avaliação são decorrentes de inspeção e testes, e existem para assegurar que os produtos produzidos atendam às necessidades dos clientes internos e externos".

Para Robles Jr (2003), os custos de avaliação são aqueles relacionados com processos realizados na identificação de produtos defeituosos, antes desses chegarem aos clientes e citam algumas atividades que provocam esses custos, tais como:

a) equipamentos e suprimentos utilizados nos testes e inspeções;

b) avaliação de protótipos;

c) novos materiais;

d) testes e inspeções nos materiais comprados;

e) testes e inspeções nos componentes fabricados;

f) métodos e processos;

g) inspeções e auditoria das operações de manufatura.

\subsection{Custos de falhas no controle}

Os custos de falhas no controle são aqueles custos encontrados durante a fabricação do produto ou mesmo quando este já foi para seu consumidor final, dizem Sato e Almeida (2007). Esses tipos de custos podem ser divididos em custos de falhas internas e custos de falhas externas.

As falhas internas são aquelas ocorridas dentro do ambiente interno da empresa, de onde, no momento da fabricação, um produto não saiu com as especificações determinadas pela qualidade, 
apresentando defeitos. Os custos gerados por estas falhas ocorrem antes da entrega do produto a seu consumidor final (SÁ, 2003).

Sá (2003) e Robles Jr (2003) mencionam alguns custos de atividades que estão relacionados às falhas internas:

a) retrabalho;

b) redesenhos;

c) refugos e sucatas;

d) tempo perdido devido à deficiência do projeto;

e) tempo perdido devido à compra de materiais defeituosos;

f) compras não planejadas;

g) descontos nos preços de vendas de produtos com pequenos defeitos;

h) atrasos na produção e entrega gerando multas e penalidades;

i) não-aplicação de reajustes de preços de novas tabelas;

j) inspeção de lotes retrabalhados;

k) manutenção corretiva;

1) horas extras para recuperar atrasos.

Todos esses custos mencionados anteriormente, para Fons (2012), representam uma quantia de dinheiro causada por desvios de objetivos e especificações, tanto em operações geradoras de saídas que são rejeitadas e descartadas, como em atividades extras que são realizadas para reparar os produtos defeituosos e serviços.

Em relação às falhas externas, Robles Jr (2003, p.68), afirma que "Os Custos das Falhas Externas decorrem das atividades relacionadas com a correção dos defeitos constatados pelos clientes". O autor acrescenta ainda que "essa correção implica, em termos de custos, o reconhecimento de todos os gastos com a remoção, correção e colocação em operação do produto nas dependências do cliente". Na visão de Maher (2001), os custos originados por falhas externas são aqueles detectados após os produtos serem entregues ao seu consumidor final.

\subsection{Mensuração dos custos da qualidade}

Os custos da qualidade são obtidos através dos controles de custo de prevenção, avaliação, falhas internas e externas de uma empresa ou negócio. Para que se possam mensurar esses custos, é necessário fazer uso de algumas informações constantes nos relatórios de contabilidade, a fim de dar continuidade a este cálculo, afirmam Porton e Goulart (2009). Ainda para Porton e Goulart (2009, p. 4) "a mensuração dos custos da qualidade está condicionada a estruturação dos valores obtidos por meio da contabilidade com as informações coletadas junto à gestão da qualidade". Para Robles Jr (2003), além dessas informações fornecidas pela contabilidade, deverá haver informações extracontábeis para que se possa formar a base para a mensuração dos custos da qualidade. 
Segundo Cusin et al. (2011), para compor os valores dos custos da qualidade é necessário marcar com que frequência certa falha vem ocorrendo, por exemplo a falha interna, o tempo ou o número de vezes que esta ocorreu em um período determinado. Após, é atribuído um valor em moeda que, em seguida, é confrontado com as bases de mensurações. Os mesmos autores sugerem alguns indicadores de controle e mensuração dos custos da qualidade, indicadores estes que estão evidenciados no Quadro 1.

Quadro 1 - Indicadores de mensuração dos custos da qualidade

\begin{tabular}{|l|c|}
\hline \multicolumn{1}{|c|}{ Indicadores } & \multicolumn{1}{|c|}{ Fórmula } \\
\hline $\begin{array}{l}\text { Índices de falhas internas: mede o valor dos custos das falhas internas, em } \\
\text { relação aos custos de produção; }\end{array}$ & $\frac{\text { IFI = Valor falhas internas }}{\text { Total de custos de produção }}$ \\
\hline $\begin{array}{l}\text { Indicador de retrabalho, em relação à mão-de-obra: este indicador mede } \\
\text { em percentual quanto de retrabalho foi feito em relação à mão-de-obra } \\
\text { produtiva; }\end{array}$ & $\underline{\text { IRM = Valor de retrabalho do mês }}$ \\
\hline $\begin{array}{l}\text { Índice de retrabalho em unidades: mede a quantidade de peças } \\
\text { retrabalhadas, em relação às peças produzidas; }\end{array}$ & $\frac{\underline{\text { Custo da mão-de-obra total }}}{\text { Unidades produzidas }}$ \\
\hline $\begin{array}{l}\text { Indicador de sucata: mede o valor da sucata, em relação ao total de } \\
\text { unidade produzidas; }\end{array}$ & $\frac{\text { IS = Unidade de sucata }}{\text { Total de unidades produzidas }}$ \\
\hline $\begin{array}{l}\text { Indicador de inspeção: mede o valor das horas em inspeção de produtos, } \\
\text { em relação ao valor das vendas do período; }\end{array}$ & $\frac{\text { I = Valor das inspeções (horas) }}{\text { Valor vendas líquidas }}$ \\
\hline $\begin{array}{l}\text { Indicador de treinamento: mede o valor do treinamento em relação ao total } \\
\text { de mão-de-obra produtiva; }\end{array}$ & $\frac{\text { IT = Valor de treinamento }}{\text { Custo da mão-de-obra total }}$ \\
\hline $\begin{array}{l}\text { Índices de falhas externas: mede o valor dos custos das falhas externas, em } \\
\text { relação ao valor das vendas líquidas; }\end{array}$ & $\frac{\text { IFE = Valor falhas externas }}{\text { Valor vendas líquidas }}$ \\
\hline $\begin{array}{l}\text { Índice de satisfação dos clientes: mede o percentual de reclamações, em } \\
\text { relação ao total de produtos/serviços vendidos. }\end{array}$ & $\frac{\text { ISC = Reclamações/produtos devolvidos }}{\text { Valor vendas líquidas }}$ \\
\hline
\end{tabular}

Fonte: Cusin et al (2011, p. 13)

Diante dos indicadores propostos por Cusin et al (2011), os autores concluem que, para cada medida, quanto menor o resultado obtido por período, melhor será para a companhia, que, para diminuir os custos com falhas, retrabalhos, desperdícios, entre outros, terá de não só anotar, como também calcular os gastos gerados por esses produtos que estão fora dos padrões exigidos pela qualidade.

\section{Princípio de Pareto}

Segundo Oliveira ([200-?]), o princípio de Pareto, ou, como alguns chamam, princípio 80/20, explana que em qualquer grupo de pessoas, empresas ou conjunto de coisas, algumas são mais significativas do que outras. O mesmo autor ([200-?], p.2) complementa dizendo que "uma boa hipótese ou referência é que $80 \%$ dos resultados ou consequências são obtidos a partir de $20 \%$ das causas ou insumos e às vezes até de uma proporção menor de forças extremamente poderosas".

Para Oliveira, Allora e Sakamoto (2006, p.39), o Pareto é uma "técnica de análise de causas, com base nos princípios desenvolvidos pelo economista Vilfredo Pareto. Segundo esses princípios, apenas uma minoria da população detém maior parte da renda". O Pareto faz com que se possam verificar as causas de um problema da maior para a menor gravidade, possibilitando identificar claramente as origens do problema e verificar o que é prioridade, salientam os mesmos autores. No 
caso da qualidade, o Pareto é uma ferramenta que contribui consideravelmente na busca das causas e origem de não conformidades, por exemplo. Oliveira, Allora e Sakamoto (2006, p. 40) citam alguns exemplos de aplicações para as quais o Pareto é utilizado:

a) identificar, detalhar e analisar problemas (erros, falhas, gastos, retrabalhos, etc.) e suas respectivas causas (operador, equipamento, matéria-prima, etc.);

b) estratificar, visualizar e priorizar as ações que focalizam os melhores resultados;

c) confirmar os resultados das ações de melhoria;

d) detalhar as causas maiores dos problemas e os itens responsáveis pelos maiores impactos objetivando a eliminação da causa.

\section{Indústria metal mecânica}

Segundo Tauffer (2010, apud MACEDO e CAMPOS, 2001), a indústria metal mecânica compreende desde as indústrias que objetivam a produção, assim como as indústrias que trabalham na transformação de metais. Tauffer (2010, p. 27) cita alguns exemplos de empresas de bens e serviços intermediários que se enquadram nesse ramo: "fundição, forjarias, oficinas de corte, soldagem, etc." e quanto a estabelecimentos destinados aos produtos finais: "bens de consumo, equipamentos, maquinaria, veículos e material de transporte”.

\subsection{Setor metal mecânico de Caxias do Sul - RS}

Segundo dados do Simecs (2012), o município de Caxias do Sul possui 42,5\% de indústrias na cidade, sendo grande parte deste percentual do setor metal mecânico. A forte concorrência entre as indústrias deste segmento faz com que o setor produtivo caxiense invista em qualidade nos seus produtos, conseguindo, assim, expandir seus negócios em nível nacional e internacional.

O setor metal mecânico tem como seu principal fornecedor as indústrias de aço e ferro. Segundo Chaib (2005, p.510), ”Os produtos fabricados na indústria de metal-mecânica destinam-se a diversos tipos de segmentos industriais, tais como: automobilística, hidro-mecânica, siderúrgica, naval, papel e celulose, mineração, construção civil, dentre outros".

\section{Identificação das principais origens do custo gerado por falhas internas no setor produtivo na empresa Alfa}

Com objetivo de manter a privacidade da empresa objeto do estudo de caso ela será identificada como Alfa. A empresa Alfa é uma sociedade de capital aberto cujo principal ramo é a fabricação de cilindros hidráulicos. Sua fábrica é dividida em diversas células, que são: célula hastes, componentes, simples ação, retro, flexível, agrícola, velha, especial e pesada, sendo que cada célula produz cilindros com diferentes especificações.

Os componentes usados na produção dos cilindros fabricados por essas células passam por diversos setores durante sua fabricação até estes chegarem ao seu consumidor final, entre eles, 
corte, solda, usinagem, montagem, pintura, entre outros. No decorrer deste percurso, esses produtos muitas vezes sofrem algumas não conformidades que acabam acarretando em custos para a empresa.

Entre os principais componentes utilizados na fabricação do cilindro - produto chave da empresa Alfa - estão: haste, êmbolo, camisa, conjunto da camisa, gaxeta, guia, mancal, bucha, anel, fundo, entre outros. O custo de cada uma das peças citadas, anteriormente, que são "mortas" na fábrica, é segregado ao custo do lote de peças boas, sendo que as peças refugadas são identificadas com etiquetas e, posteriormente, é feito um relatório de não conformidade (RNC) para registrar o seu sucateamento. O mesmo ocorre com as peças que necessitam serem retrabalhadas. Estas seguem o mesmo processo e, após ser feito o RNC, elas são encaminhadas ao setor responsável pelo retrabalho e depois retornam à linha normal de produção. É através dos RNCs lançados no sistema que a empresa Alfa controla o andamento desses produtos "defeituosos".

Pelos dados levantados junto à empresa Alfa, só no ano de 2012, foram produzidos 1.025.161 componentes (camisas, guias, êmbolos, hastes, entre outros), produtos esses que são utilizados na fabricação dos cilindros. Destes componentes produzidos, 2.218 foram refugados pela fábrica, ou seja, $0,22 \%$ das peças produzidas foram sucateadas. No caso dos produtos prontos, foram produzidos 135.164 cilindros neste mesmo período, sendo que destes, 1.713 tiveram que ser retrabalhados, ou seja, 1,27\% da produção total saíram com algum defeito, mas que foi possível reparar. É possível verificar quanto isso representa na Tabela 1, comparando com o custo dos produtos vendidos.

Tabela 1 - Custo das peças defeituosas x CPV

\begin{tabular}{l|r|r}
\hline Nomenclatura & \multicolumn{1}{|c}{ Custo } & \multicolumn{1}{c}{$\%$} \\
\hline Peças refugadas & $193.785,25$ & $0,31 \%$ \\
\hline Peças retrabalhadas & $36.576,21$ & $0,06 \%$ \\
\hline CPV & $61.744 .565,56$ & $100 \%$ \\
\hline
\end{tabular}

Fonte: Elaboração dos autores

Conforme se pode verificar na Tabela 1 , as peças refugadas representam $0,31 \%$ do custo dos produtos vendidos da empresa, enquanto as peças retrabalhadas representam $0,06 \%$, cinco vezes menos que as refugadas. Se for considerado apenas o percentual, o custo total de peças defeituosas não é tão representativo, já que a soma dos dois tipos de custos não chega a representar $0,5 \%$ do total do custo de produção. No entanto, se for considerado o custo em reais das peças refugadas e retrabalhadas, ele representa mais de $\mathrm{R} \$ 230.000,00$, no ano de 2012. Esse número representa valores que são desperdiçados em função desses custos com refugos e retrabalhos, ou seja, se não houvesse essas falhas, este valor poderia ser empregado em melhorias na fábrica, compra de máquinas, aprimoramento de condições de trabalho para os funcionários ou até mesmo reversão em aumento do resultado. 
Devido ao percentual de peças refugadas ser mais significativo do que o de retrabalhadas, foi decido que o estudo de caso trataria das origens do custo que as peças refugadas geram.

\subsection{Análise das células}

Em função de a empresa Alfa possuir várias células produtivas e pela impossibilidade do estudo conseguir fazer a análise de todas elas, foram escolhidas aleatoriamente três células para serem analisadas, são elas: célula agrícola, célula retro e célula velha. O período analisado foi o ano de 2012. Os dados utilizados pela pesquisa foram disponibilizados pela área de custos e de qualidade da empresa Alfa, sendo eles tabulados e analisados pelos autores.

\subsubsection{Célula agrícola}

A célula agrícola, como o próprio nome sugere é uma célula destinada à fabricação de componentes hidráulicos para as linhas agrícolas, também conhecidas como linha verde. Podem-se citar algumas máquinas que fazem uso dos cilindros produzidos por essa célula: colheitadeiras, plantadeiras, pulverizadores, tratores, entre outros.

Após apurados os dados relativos à célula agrícola, foi possível analisar certos fatos ocorridos no ano de 2012 na referida célula. Na Tabela 2 estão demonstradas as causas decorrentes de falhas internas identificadas na célula agrícola, sendo estas originadas em diferentes setores da área fabril da empresa, objeto do estudo de caso.

Tabela 2 - Peças refugadas - Célula agrícola

\begin{tabular}{|c|c|c|c|c|c|}
\hline \multicolumn{2}{|c|}{ Causas das peças refugadas } & \multirow{2}{*}{$\begin{array}{l}\text { Quantidade de } \\
\text { peças refugadas }\end{array}$} & \multicolumn{3}{|c|}{ Valor do custo } \\
\hline Descrição & Origem & & Materiais & Mão de obra & Total \\
\hline Erro de Montagem & Montagem & 3 & 12,58 & 9,41 & 65,97 \\
\hline Peças com Batidas & Montagem & 5 & 11,10 & 7,61 & 93,55 \\
\hline Peças mal acondicionadas & Montagem & 20 & 58,24 & 31,87 & $1.802,20$ \\
\hline Peças sem acondicion.adequado & Montagem & 7 & 48,76 & 14,76 & 444,64 \\
\hline \multicolumn{2}{|l|}{ Total Montagem } & 35 & & & $2.406,36$ \\
\hline Erro Dimensional & Solda & 21 & 15,40 & 3,37 & 394,17 \\
\hline Erro do Operador & Solda & 6 & 33,81 & 31,16 & 389,82 \\
\hline Outros & Solda & 7 & 40,59 & 16,98 & 402,99 \\
\hline \multicolumn{2}{|l|}{$\begin{array}{r}\text { Total Solda } \\
\end{array}$} & 34 & & & $1.186,98$ \\
\hline Erro Concentricidade & Usinagem & 4 & 27,12 & 12,92 & 160,16 \\
\hline Erro de Preparação & Usinagem & 10 & 33,57 & 20,98 & 545,50 \\
\hline Erro de Programa & Usinagem & 5 & 25,61 & 12,16 & 188,85 \\
\hline Erro de Usinagem & Usinagem & 1 & 23,47 & 23,62 & 47,09 \\
\hline Erro Dimensional & Usinagem & 103 & 41,45 & 20,77 & $6.408,66$ \\
\hline Erro do Operador & Usinagem & 85 & 46,23 & 21,44 & $5.751,95$ \\
\hline Máquina sem condições & Usinagem & 4 & 30,50 & 24,38 & 219,52 \\
\hline Materiais com trinca & Usinagem & 3 & 29,57 & 20,98 & 151,65 \\
\hline Materiais errados & Usinagem & 7 & 27,12 & 27,45 & 381,99 \\
\hline Peças mal acondicionadas & Usinagem & 1 & 34,10 & 20,85 & 54,95 \\
\hline Problemas c/ dispositivo / ferram & Usinagem & 32 & 49,66 & 31,03 & $2.582,08$ \\
\hline Rosca folgada/apertada/danificada & Usinagem & 3 & 14,17 & 25,66 & 119,49 \\
\hline \multicolumn{2}{|l|}{$\begin{array}{c}\text { Total Usinagem } \\
\end{array}$} & 258 & & & $16.611,89$ \\
\hline \multicolumn{2}{|l|}{ TOTAL } & 327 & & & $20.205,23$ \\
\hline
\end{tabular}

Fonte: Empresa Alfa, adaptado pelos autores 
Conforme evidenciado na Tabela 2, diversos são os motivos que dão origem às causas que geraram os custos, em relação a peças refugadas, na célula agrícola. É possível perceber que o setor que mais origina custo nesta linha é o setor de usinagem. Este representa $82,22 \%$ dos custos originados por falhas, enquanto a montagem representa $11,91 \%$ e a solda $5,87 \%$.

De acordo com o princípio de Pareto, deve-se "estabelecer uma ordem ou priorização nas causas de problemas das mais diversas naturezas", dizem Oliveira, Allora e Sakamoto (2006, p.40). Com base nessa premissa, pode-se partir do pressuposto de que é necessário verificar primeiramente o que gera maior custo para a empresa, para assim, focar na solução dessas causas, a fim de reduzir as falhas e, consequentemente, minimizar os custos gerados por elas. No caso da célula agrícola, o setor que mais se destaca por elevados custos gerados por falhas é o setor da usinagem, mas, antes de entrar em detalhes nesse setor, é de grande importância também observar os setores de solda e montagem, que juntos representam quase $20 \%$ dos problemas da célula.

Os erros por mal-acondicionamento nas peças são as falhas que mais se destacam na montagem, gerando $\mathrm{R} \$ 1.802,20$ num total de 20 peças, o que dá em média $\mathrm{R} \$ 90,11$ de custo de refugo por peça. Já na solda, os erros dimensionais são os que se destacam, mas, ao contrário do erro citado anteriormente, estes somam um total de 21 peças, gerando um custo de refugo em média de $\mathrm{R} \$ 18,77$ por peça. A principal causa de geração de custo na usinagem é devido a erros dimensionais, ou seja, peças com medidas diferentes do padrão especificado, sendo essas muitas vezes adquiridas do fornecedor já com a falha de dimensão e não sendo detectada pelo controle de qualidade antes desta ir para a linha de produção. Apenas este erro absorve 38,58\% do custo de toda usinagem, gerando $\mathrm{R} \$ 6.408,66$ num total de 103 peças, com um custo médio de $\mathrm{R} \$ 62,22$ por peça. Se comparado ao custo por peça do erro dimensional na solda, temos uma diferença de $\mathrm{R} \$$ 43,45 a mais na usinagem, ou seja, o valor do refugo é 70\% mais caro na usinagem do que na solda. Em seguida, com $34,63 \%$, estão as falhas geradas por erro do operador, ou seja, falha provocada por erro humano. Somente essas duas falhas, dimensional e de operador, no setor da usinagem absorvem mais de $70 \%$ dos custos gerados neste setor, e mais de $60 \%$ em toda célula.

Se forem considerados custos de usinagem juntamente com o setor de solda, ter-se-ia mais $1,95 \%$ de erros dimensionais e $1,93 \%$ de erro do operador, totalizando em $64,07 \%$ o custo gerado por essas duas falhas, ou seja, mais da metade dos custos da célula agrícola são causados por esses dois erros.

É relevante destacar também os erros com dispositivos e ferramentas que representam $15,54 \%$ dos custos na usinagem, e 12,78\% no total da célula agrícola, ficando este em terceiro lugar nas principais causas geradoras de custos nesta célula. 


\subsubsection{Célula retro}

O foco da célula retro é a fabricação de cilindros hidráulicos para construção civil (linha amarela), um setor que vem crescendo gradativamente com o passar dos anos. Os cilindros fabricados por essa linha são utilizados em máquinas como: retro escavadeira, carregadeiras, caminhões fora de estrada, entre outros.

Os dados levantados relativos à célula retro estão evidenciados na Tabela 3 , na qual é possível identificar as principais causas de falhas internas e os custos dessa célula. Com base nos dados apresentados na Tabela 4, é possível identificar que, assim como a célula agrícola, o setor de maior geração de custos na célula retro é o setor de usinagem. Este absorve mais de $70 \%$ da célula, enquanto a solda $26,30 \%$ e a montagem menos de $1 \%$. Se comparada à célula agrícola, a célula retro teve um desempenho um pouco melhor gerando $\mathrm{R} \$ 16.289,72$ de custo, num total de 155 peças refugadas, enquanto que a célula agrícola gerou $\mathrm{R} \$ 20.205,23$ de custos, porém, com o dobro de peças refugadas. Pode-se verificar, então, que, conforme as Tabelas 2 e 3, o custo de matériaprima da maioria dos produtos da célula retro é superior ao da agrícola, tornando seu custo mais alto.

Somente o setor da usinagem, nesta célula, contribuiu com R \$ 11.915,03, isto é, 73,14\% nos custos de falhas internas em 2012, num total de 120 peças refugadas. A principal causa geradora de custos, no setor de usinagem, é o erro dimensional, absorvendo $63,11 \%$ dos custos neste departamento, sendo $52,86 \%$ de toda célula retro, se somados com o setor de usinagem e solda. Mais uma vez, se comparado com a célula agrícola, o erro dimensional fica em primeiro lugar como principal causador de custos de falhas internas. Neste caso, os erros dimensionais ultrapassam mais da metade dos gastos com refugos na célula retro.

Tabela 3 - Peças refugadas - Célula retro

\begin{tabular}{|c|c|c|c|c|c|}
\hline \multicolumn{2}{|l|}{ Causas das peças refugadas } & \multirow{2}{*}{$\begin{array}{c}\text { Quantidade de peças } \\
\text { refugadas }\end{array}$} & \multicolumn{3}{|c|}{ Valor do custo } \\
\hline Descrição da causa & Origem & & Materiais & Mão de obra & Total \\
\hline Erro de Montagem & Montagem & 2 & 19,41 & 10,54 & 59,90 \\
\hline Instrumento Inadequado & Montagem & 1 & 14,46 & 16,65 & 31,11 \\
\hline \multicolumn{2}{|l|}{$\begin{array}{c}\text { Total Montagem } \\
\end{array}$} & 3 & & & 91,01 \\
\hline Erro de Dispositivo & Solda & 4 & 119,32 & 32,17 & 605,96 \\
\hline Erro de Programa & Solda & 2 & 102,32 & 27,09 & 258,82 \\
\hline Erro Dimensional & Solda & 9 & 100,49 & 20,74 & $1.091,07$ \\
\hline Falta de Penetração & Solda & 5 & 75,14 & 14,26 & 447,00 \\
\hline Máquina sem condições & Solda & 4 & 129,03 & 63,58 & 770,44 \\
\hline Outros & Solda & 7 & 104,32 & 14,79 & 833,77 \\
\hline Solda componente errado & Solda & 1 & 237,96 & 38,66 & 276,62 \\
\hline \multicolumn{2}{|l|}{ Total Solda } & 32 & & & $4.283,68$ \\
\hline Acabamento Superficial & Usinagem & 10 & 47,37 & 19,67 & 670,40 \\
\hline Erro de Usinagem & Usinagem & 6 & 32,43 & 169,70 & $1.212,78$ \\
\hline Erro Dimensional & Usinagem & 78 & 74,79 & 21,62 & $7.519,98$ \\
\hline Erro do Operador & Usinagem & 5 & 78,84 & 22,38 & 506,10 \\
\hline Máquina sem condições & Usinagem & 11 & 98,86 & 31,82 & $1.437,48$ \\
\hline Outros & Usinagem & 6 & 23,80 & 7,97 & 190,62 \\
\hline Regulagem medida errada & Usinagem & 1 & 40,84 & 138,95 & 179,79 \\
\hline Rosca folgada / apertada / danificada & Usinagem & 3 & 38,88 & 27,08 & 197,88 \\
\hline \multicolumn{2}{|l|}{ Total Usinagem } & 120 & & & $11.915,03$ \\
\hline
\end{tabular}




\section{TOTAL}

Fonte: Empresa Alfa, adaptada pelos autores.

Em segundo lugar, podem-se destacar as falhas por máquinas sem condições de produção com $12,06 \%$ e os erros de usinagem com 10,18\%. Ao contrário da célula agrícola, os erros de operador na célula retro ficam bem abaixo, com $4,25 \%$.

\subsubsection{Célula velha}

A célula velha, diferentemente das outras citadas anteriormente, não tem uma área específica de produção, esta fabrica diversos tipos de cilindros para vários setores, como construção civil, agrícola, automotivo, guindastes, industriais e especiais. Pode-se citar como exemplo caminhões de lixo, carretas, retro escavadeira, guindastes, colheitadeiras, entre outros que fazem uso dos cilindros produzidos nessa célula.

Não sendo diferente das duas células analisadas anteriormente, a célula velha também leva como maior causador de falhas o setor da usinagem. Neste caso, o setor de usinagem ultrapassou as outras células, representando quase $90 \%$, ou seja, os erros encontrados nesta célula são praticamente todos por problemas de usinagem. O setor de montagem representa $4,11 \%$, enquanto o setor de solda fica com $6,21 \%$.

$\mathrm{Na}$ Tabela 4 é possível visualizar as causas de falhas internas e os custos gerados por elas de cada setor produtivo na célula velha e com isso constatar a grande participação da usinagem no total do custo de peças refugadas da Célula velha. Mesmo o setor de usinagem sendo o mais "problemático", pode-se perceber, com base nos dados contidos na Tabela 5, que alguns dos custos com materiais são bastante elevados neste setor, sendo um dos motivos que torna seu custo maior. No setor da solda e da montagem também pode-se verificar que dois dos tipos de falhas têm custo de materiais bem elevados, mas, como o número de peças refugadas nesses setores não é tão expressivo quanto o da usinagem, eles acabam não se tornando o principal alvo gerador de custo.

É relevante evidenciar que enquanto na célula agrícola e retro os erros dimensionais gerados na usinagem têm um custo por peça de $\mathrm{R} \$ 62,22$ e $\mathrm{R} \$ 96,41$, respectivamente, na velha eles custam R \$ 341,97, unitário. Esse valor é cinco vezes superior à célula agrícola e três vezes superior à retro. Diferentemente da célula agrícola e retro, na célula velha o principal gerador de custos no setor da usinagem são os erros de projeto, absorvendo $34,73 \%$.

Tabela 4 - Peças refugadas - Célula velha

\begin{tabular}{|c|c|c|c|c|c|}
\hline \multicolumn{2}{|c|}{ Causas das peças refugadas } & \multirow{2}{*}{$\begin{array}{c}\text { Quantidade de peças } \\
\text { refugadas }\end{array}$} & \multicolumn{3}{|c|}{ Valor do custo } \\
\hline Descrição da Causa & Origem & & Materiais & Mão de obra & Total \\
\hline Materiais Errados & Montagem & 11 & 54,21 & 21,36 & 831,27 \\
\hline Peças com Batidas & Montagem & 20 & 32,45 & 19,46 & $1.038,20$ \\
\hline Peças sem acondicion. adequado & Montagem & 3 & 147,57 & 32,02 & 538,77 \\
\hline \multicolumn{2}{|l|}{$\begin{array}{l}\text { Total Montagem } \\
\end{array}$} & 23 & & & $2.408,24$ \\
\hline Erro Dimensional & Solda & 10 & 198,50 & 66,52 & $2.650,20$ \\
\hline Falha de matéria prima & Solda & 2 & 16,57 & 15,66 & 64,46 \\
\hline Erro do Operador & Solda & 14 & 38,29 & 23,86 & 870,10 \\
\hline
\end{tabular}




\begin{tabular}{|c|c|c|c|c|c|}
\hline Material Errado & Solda & 1 & 41,58 & 14,65 & 56,23 \\
\hline \multicolumn{2}{|l|}{ Total Solda } & 27 & & & $3.640,99$ \\
\hline Erro de Preparação & Usinagem & 1 & 78,84 & 24,34 & 103,18 \\
\hline Erro de Projeto & Usinagem & 28 & 631,00 & 21,22 & $18.262,16$ \\
\hline Erro Dimensional & Usinagem & 43 & 237,06 & 104,91 & $14.704,71$ \\
\hline Erro do Operador & Usinagem & 139 & 85,54 & 24,58 & $15.306,68$ \\
\hline Materiais com Trinca & Usinagem & 2 & 166,24 & 43,73 & 419,94 \\
\hline Outros & Usinagem & 5 & 82,18 & 28,03 & 551,05 \\
\hline Peças sem acondicion. adequado & Usinagem & 11 & 48,76 & 14,76 & 698,72 \\
\hline Problemas c/ dispositivo / ferram & Usinagem & 19 & 111,60 & 22,12 & $2.540,68$ \\
\hline \multicolumn{2}{|l|}{ Total Usinagem } & 248 & & & $52.587,12$ \\
\hline TOTAL & & 298 & & & $\mathbf{5 8 . 6 3 6 , 3 5}$ \\
\hline
\end{tabular}

Fonte: Empresa Alfa, adaptada pelos autores.

Esses erros ocorrem, devido a algum erro no cadastro de informações do produtos, no sistema, na maioria das vezes por desatenção do funcionário que faz o cadastro. Em segundo lugar, estão os erros de operador, absorvendo $29,11 \%$ dos custos. Essa falha se deve, na maioria das vezes, pela própria desatenção do operador, por exemplo, ao fazer uma peça, este pode utilizar a ferramenta errada ou até mesmo pegar a peça diferente da especificada no momento da montagem do cilindro, no caso delas serem parecidas.

É importante evidenciar ainda os erros dimensionais que, ao contrário das outras células, na célula velha ficam em terceiro lugar com $27,96 \%$ dos custos no setor da usinagem, mas representando quase $30 \%$ no total de toda célula, se somado com o setor de solda.

\subsection{Análise geral}

Considerando-se os dados levantados, percebeu-se que, nas três células analisadas, as principais origens dos custos de peças refugadas ocorrem no setor de usinagem, tendo como fatores principais os erros do operador, de projeto e dimensional. Com base nessa informação, entendeu-se ser interessante proceder a um levantamento nas demais células de forma a identificar se essa constatação também ocorre nelas.

A Tabela 5 evidencia esse levantamento, na qual se pode observar quais são as principais causas geradoras dos custos relacionados com as peças refugadas, de cada célula, juntamente com seus custos e o percentual que cada uma representa sobre o total de custos com refugos, de cada célula, respectivamente, e também sobre o total geral. Para análise das principais falhas, não será considerado o item das demais causas, que se refere a diversas causas, mas cada uma com um percentual pequeno, detendo-se às causas identificadas.

Como ocorreu nas três células analisadas, a usinagem continua sendo o setor que mais se destaca na geração de custos de refugos também nas demais células, sendo que o total do gasto gerado por esse setor representa 60,96\% do total registrado pela empresa. Com exceção da célula simples ação (Tabela 5), todas as outras células têm como umas das causas principais o erro 
dimensional, ficando este em primeiro lugar como principal gerador de custos de refugos com $35,67 \%$, gerando quase $\mathrm{R} \$ 70.000,00$ de custos para a empresa.

Tabela 5 - Principais causas geradoras de custos

\begin{tabular}{|c|c|c|c|c|c|}
\hline Célula & Causa & Origem & Custo & $\%$ s/ Célula & $\%$ s/ Total \\
\hline \multirow{5}{*}{ Célula agrícola } & Erro Dimensional & Usinagem & $6.408,66$ & $31,72 \%$ & $3,31 \%$ \\
\hline & Erro do Operador & Usinagem & $5.751,95$ & $28,47 \%$ & $2,97 \%$ \\
\hline & \multicolumn{2}{|l|}{ Subtotal } & $12.160,61$ & $60,19 \%$ & $6,28 \%$ \\
\hline & Demais causas & Geral & $8.044,62$ & $39,81 \%$ & $4,15 \%$ \\
\hline & \multicolumn{2}{|l|}{ Total } & $20.205,23$ & $100 \%$ & $10,43 \%$ \\
\hline \multirow{4}{*}{ Célula retro } & Erro Dimensional & Usinagem & $7.519,98$ & $46,16 \%$ & $3,88 \%$ \\
\hline & \multicolumn{2}{|l|}{ Subtotal } & $7.519,98$ & $46,16 \%$ & $3,88 \%$ \\
\hline & Demais causas & Geral & $8.769,74$ & $53,84 \%$ & $4,53 \%$ \\
\hline & \multicolumn{2}{|l|}{ Total } & $16.289,72$ & $100 \%$ & $8,41 \%$ \\
\hline \multirow{6}{*}{ Célula velha } & Erro de Projeto & Usinagem & $18.262,16$ & $31,14 \%$ & $9,42 \%$ \\
\hline & Erro Dimensional & Usinagem & $14.704,71$ & $25,08 \%$ & $7,59 \%$ \\
\hline & Erro do Operador & Usinagem & $15.306,68$ & $26,10 \%$ & $7,90 \%$ \\
\hline & Subtotal & & $48.273,55$ & $82,33 \%$ & $24,91 \%$ \\
\hline & Demais causas & Geral & $10.362,80$ & $17,67 \%$ & $5,35 \%$ \\
\hline & \multicolumn{2}{|l|}{$\begin{array}{r}\text { Total } \\
\end{array}$} & $58.636,35$ & $100 \%$ & $30,26 \%$ \\
\hline \multirow{6}{*}{$\begin{array}{c}\text { Célula } \\
\text { componentes }\end{array}$} & Erro Dimensional & Usinagem & $13.330,24$ & $39,98 \%$ & $6,88 \%$ \\
\hline & Erro do Operador & Usinagem & $6.755,00$ & $20,26 \%$ & $3,49 \%$ \\
\hline & Prob. c/ dispositivo /ferram & Usinagem & $4.337,58$ & $13,01 \%$ & $2,24 \%$ \\
\hline & Subtotal & & $24.422,82$ & $73,25 \%$ & $12,60 \%$ \\
\hline & Demais causas & Geral & $8.917,21$ & $26,75 \%$ & $4,60 \%$ \\
\hline & \multicolumn{2}{|l|}{ Total } & $33.340,03$ & $100 \%$ & $17,20 \%$ \\
\hline \multirow{5}{*}{ Célula especial } & Erro de Roteiro & Usinagem & 961,68 & $13,23 \%$ & $0,50 \%$ \\
\hline & Erro Dimensional & Montagem & $4.050,05$ & $55,70 \%$ & $2,09 \%$ \\
\hline & Subtotal & & $5.011,73$ & $68,93 \%$ & $2,59 \%$ \\
\hline & Demais Causas & Geral & $2.259,05$ & $31,07 \%$ & $1,17 \%$ \\
\hline & Total & & $7.270,78$ & $100 \%$ & $3,75 \%$ \\
\hline \multirow{4}{*}{$\begin{array}{l}\text { Célula } \\
\text { Flexível }\end{array}$} & Erro Dimensional & Usinagem & 374,64 & $31,54 \%$ & $0,19 \%$ \\
\hline & \multicolumn{2}{|l|}{ Subtotal } & 374,64 & $31,54 \%$ & $0,19 \%$ \\
\hline & Demais Causas & Geral & 813,28 & $68,46 \%$ & $0,42 \%$ \\
\hline & \multicolumn{2}{|l|}{ Total } & $1.187,92$ & $100 \%$ & $0,61 \%$ \\
\hline \multirow{5}{*}{ Célula hastes } & Erro Dimensional & Usinagem & $4.630,00$ & $50,57 \%$ & $2,39 \%$ \\
\hline & Erro de Operador & Usinagem & $1.687,68$ & $18,43 \%$ & $0,87 \%$ \\
\hline & Subtotal & & $6.317,68$ & $69,01 \%$ & $3,26 \%$ \\
\hline & Demais Causas & Geral & $2.837,09$ & $30,99 \%$ & $1,46 \%$ \\
\hline & \multicolumn{2}{|l|}{ Total } & $9.154,77$ & $100 \%$ & $4,72 \%$ \\
\hline \multirow{5}{*}{ Célula pesada } & Erro Dimensional & Usinagem & $18.107,10$ & $49,42 \%$ & $9,34 \%$ \\
\hline & Falha de Tratat. Superficial & Serv. Exter. & $7.056,00$ & $19,26 \%$ & $3,64 \%$ \\
\hline & Subtotal & & $25.163,10$ & $68,68 \%$ & $12,99 \%$ \\
\hline & Demais Causas & Geral & $11.476,30$ & $31,32 \%$ & $5,92 \%$ \\
\hline & Total & & $36.639,40$ & $100 \%$ & $18,91 \%$ \\
\hline & Erro de Operador & Corte & $3.350,00$ & $30,29 \%$ & $1,73 \%$ \\
\hline & Material cortado a menor & Corte & $2.055,00$ & $18,58 \%$ & $1,06 \%$ \\
\hline Célula simples ação & $\begin{array}{r}\text { Subtotal } \\
\end{array}$ & & $5.405,00$ & $48,87 \%$ & $2,79 \%$ \\
\hline & Demais Causas & Geral & $5.656,05$ & $51,13 \%$ & $2,92 \%$ \\
\hline & Total & & $11.061,05$ & $100 \%$ & $5,71 \%$ \\
\hline TOTAL POR & Usinagem & & $118.138,06$ & $60,96 \%$ & $-\mathrm{x}-$ \\
\hline SETOR & Demais setores & & $75.647,19$ & $39,04 \%$ & $-\mathrm{x}-$ \\
\hline & Total & & $193.785,25$ & $100 \%$ & $-\mathrm{x}-$ \\
\hline & Erro de Projeto & Geral & $18.262,16$ & $-\mathrm{X}-$ & $9,42 \%$ \\
\hline & Erro Dimensional & Geral & $69.125,38$ & $-\mathrm{X}^{-}$ & $35,67 \%$ \\
\hline TOTAL & Erro do Operador & Geral & $32.851,31$ & $-\mathrm{X}-$ & $16,95 \%$ \\
\hline & Erro de Roteiro & Geral & 961,68 & $-\mathrm{X}-$ & $0,50 \%$ \\
\hline POR & Prob. c/ dispositivo /ferram & Geral & $4.337,58$ & $-\mathrm{X}-$ & $2,24 \%$ \\
\hline CAUSA & Falha de Tratat. Superficial & Geral & $7.056,00$ & $-\mathrm{X}-$ & $3,64 \%$ \\
\hline & Material cortado a menor & Geral & $2.055,00$ & $-\mathrm{X}-$ & $1,06 \%$ \\
\hline & Demais causas & Geral & $59.136,14$ & $-\mathrm{X}-$ & $30,52 \%$ \\
\hline & $\begin{array}{r}\text { TOTAL } \\
\end{array}$ & & $193.785,25$ & $-\mathrm{X}-$ & $100 \%$ \\
\hline
\end{tabular}

Fonte: Criada pelos autores 
Em seguida, vêm os erros provocados pelo operador, representando 16,95\%, com R\$ $32.851,31$ de gastos e em terceiro lugar os erros de projetos, absorvendo 9,42\%, com $\mathrm{R} \$ 18.262,16$. Com base nessas três principais causas, procurou-se identificar, juntamente com os responsáveis em cada área, quais seriam os principais motivos da concentração das causas nos erros dimensionais, assim como nos outros dois erros.

Segundo informações obtidas junto ao responsável pelo controle desses gastos, os erros dimensionais ocorrem devido ao operador da máquina não conseguir prever o que vai acontecer durante o processo de fabricação da peça. Quando ocorre a usinagem de um lote de 100 peças, por exemplo, e, ao final do lote, somente as últimas três peças ficarem com diâmetro maior ou menor, e todas as outras ficarem corretas, isso ocorre em função do desgaste natural da ferramenta durante o processo, gerando uma desconformidade nas últimas peças. Nesses casos, o operador não tem como prever esse desgaste, pois o grau de dureza entre as peças do lote pode variar, acarretando na perda dessas três peças que saíram com diâmetro errado. Outros exemplos são os cavacos que acumulam nas peças; peças deformadas no momento da solda, alterando seu diâmetro e impossibilitando a montagem da mesma; ferramentas que quebram ao longo do processo, entre outros.

Para algumas dessas causas são realizadas ações corretivas com a finalidade de minimizar essas falhas. Por exemplo, no caso do cavaco que acumula nas peças, a empresa está avaliando a compra de um inserto que auxilie mais a saída do cavaco. Em relação à deformação das peças causada pela solda, a empresa está fazendo um estudo buscando uma alternativa para aumentar a parede do tubo ou mexer nos parâmetros da solda, a fim de minimizar o problema.

No caso de erros causados pelo operador, eles podem ocorrer de diversas maneiras. Um exemplo é a falta de atenção do funcionário, em que o desenho indica um furo com o diâmetro de $10 \mathrm{~mm}$ e o operador usa uma ferramenta errada, com diâmetro maior. $\mathrm{O}$ fato de ele utilizar uma ferramenta com diâmetro maior acaba por fazer com que a peça seja totalmente refugada, pois não há como recuperar a mesma. Se a ferramenta utilizada for com diâmetro menor, então existe a possibilidade de retrabalhar o furo e recuperar a peça.

Com relação aos erros de projetos, na maioria das vezes, as falhas ocorrem por desatenção do projetista. São coisas simples, como uma cota errada, uma vírgula fora do lugar, mas que acabam gerando um erro e muitas vezes retrabalho ou refugo das peças. Uma boa revisão no projeto antes de mandá-lo adiante com certeza diminuiria muito esses erros, mas, infelizmente, tais revisões são feitas de forma rápida e superficialmente e as consequências disso são sentidas mais adiante, diz o responsável pelo setor de engenharia da empresa Alfa.

Tendo como base as células e as falhas analisadas, chega-se a conclusão de que a empresa deveria dar prioridade na busca de alternativas para reduzir os erros que têm origem nas três 
situações acima apresentadas, já que, juntas, elas representam $60 \%$ dos custos com peças refugadas. Isso quer dizer que se a empresa conseguisse eliminar 100\% desses três problemas, poderia reduzir em $60 \%$ os custos com produtos defeituosos. Embora seja quase impossível eliminar 100\%, qualquer redução em percentual desses problemas terá um efeito superior se comparado com a mesma redução em outros problemas. Ou seja, se conseguisse reduzir em $30 \%$ o custo desses problemas, a empresa conseguiria uma redução de $18 \%$ no custo total (30\% x $60 \%$ ), o que não aconteceria se ocorresse a redução de $30 \%$ em outros problemas, por estes terem uma participação menor.

A partir dessa relação e considerando os valores dos custos apresentados no período avaliado, pode-se concluir que, uma vez mantidas essas duas situações, para cada $10 \%$ de redução desses erros há uma redução de $6 \%$ do total de seus custos com peças refugadas. Considerando os gastos levantados, essa economia corresponderia a uma redução nos custos de R $11.627,12$ para cada $10 \%$ de redução dos três principais erros. Embora se saiba que as duas relações acima consideradas, bem como o valor do custo total levantado das peças refugadas, podem não se repetir, acredita-se que elas devam se manter em patamares muito próximos, o que permite concluir que a empresa deve direcionar sua atenção especial (sem deixar de tratar das demais origens) para buscar a redução dos motivos que geram esses erros e que acabam se tornando as principais causas das origens dos custos de peças refugadas.

\section{Conclusão}

Como é de conhecimento geral, e também evidenciado ao longo deste estudo, os custos originados por falhas de qualidade de produção oneram o custo do produto, fazendo com que a empresa tenha que vender seu produto mais caro (quando ela consegue repassar para o consumidor esse custo) ou aceitar que sua margem de lucro seja menor (quando ela não tem como repassar este custo ao preço final - preço definido pelo mercado).

Nas duas situações, os custos com falhas representam um gasto desnecessário e que não agregam nenhum valor, seja para a empresa ou para o cliente. Esse tipo de custo pode fazer com que a empresa, ao repassar o custo para o produto, tenha dificuldade de enfrentar a concorrência ou, ao não repassar, tenha a perda de margem, o que pode comprometer os resultados e, inclusive, em alguns casos, afetar a sobrevivência da empresa. Diante disso, é inquestionável que o custo com falhas deva ser combatido, visando eliminá-lo ou, se impossível eliminá-lo por completo, então, reduzi-lo ao máximo.

Esses custos gerados por falhas devem-se a peças que, no momento de sua fabricação, saem com alguma não conformidade, ou seja, diferentemente do que está especificado no seu desenho ou projeto. 
Com base nisso, o estudo de caso levantou as principais causas que estão gerando custos de má qualidade para a empresa Alfa, assim como as origens dessas causas. Os levantamentos realizados permitiram concluir que o percentual de falhas internas não é tão expressivo se comparado com o valor de seu faturamento (não chegando a $0,5 \%$ do total do custo dos produtos vendidos). Porém, se considerado o valor em reais (mais de 230 mil no ano de 2012), a quantia torna-se representativa, requerendo a atenção da empresa visando buscar sua redução.

Para se conseguir uma eficaz redução de custos de peças refugadas não basta identificar as causas dos mesmos, mas também é necessário identificar quais são as causas que mais geram custos, bem como quais são os principais motivos que lhes dão origens.

Durante o estudo foi possível concluir que as três principais causas que geram maior custo de falhas para a empresa são: falhas por erros dimensionais, falhas por erros de operador e falhas por erro de projeto. Essas três causas correspondem por mais de $60 \%$ dos custos gerados por falhas na linha de produção da Alfa.

Também foi possível identificar que apenas o setor de usinagem é responsável por mais de $60 \%$ do custo das falhas. Portanto, entende-se que praticamente $100 \%$ destes três erros ocorrem no setor de usinagem, sendo que foi possível levantar que eles ocorrem por três motivos principais: desgastes nas ferramentas, desatenção do operador e do projetista, problemas no ferramental. Diante disso, entende-se que essa identificação pode contribuir para o desenvolvimento de ações por parte da empresa que visem reduzir esses três motivos, representando os grandes causadores das falhas. Reduzi-los proporcionará uma diminuição muito significativa do custo total de falhas internas que a empresa Alfa tem atualmente.

\begin{abstract}
The search to identify the root causes of internal faults and minimizing additional costs in the productive sector is increasingly present in the companies. The study aims to lift and identify the main sources of the cost generated by internal faults in the production line of a branch company of metal mechanic Caxias do Sul - RS. To this end, we used the case study as a research methodology. Based on data provided by the company, proceeded to tabulation and analysis to identify the origin of the losses that the company had failures during the year 2012. It was possible to identify the flaws, as a whole, not as a percentage, representing a very high cost for this company, when compared to the volume of sales of the same. However, the absolute cost is significant, which justifies identifying their origins and, thus, providing that actions to reduce it are evaluated. The study also raised that failures occur more concentrated form in the machining industry. Another conclusion was that there is also a large concentration of the type of error that cause failures, where more than half of the entire cost of parts is withdrawn, for three reasons : failure caused by machining error, operator error and design error. Besides the identification of the sector and the causes that generate the bulk of the cost, the study also raised the main reasons that ultimately give rise to three main causes.
\end{abstract}

Keywords: Costs. Internal failures. Internal errors. Machining. Metal-Mechanical Industry. 


\section{Referências}

ALVES, J. M. O sistema Just In Time Reduz os Custos do Processo Produtivo. In: Instituto de Fomento e Coordenação Industrial - IFI. 1995. São José dos Campos - SP. Anais eletrônicos: São José dos Campos - SP. Disponível em: 〈http://www.intercostos.org/documentos/texto8-3.pdf>. Acesso em: 5 out. 2012.

BRANDÃO, L. C. et al. A Metodologia Seis Sigma aplicada à redução do refugo de Cremalheiras para sistemas de direção. In: XXX Encontro Nacional de Engenharia de Produção, 30, 2010, São Paulo - SP. Anais eletrônicos: São Paulo: UFSJ, 2010. Disponível em <http://www.abepro.org.br/biblioteca/enegep2010_TN_STO_113_745_16053.pdf>. Acesso em: 11 set. 2012.

CHAIB, E. B. D’ A. Proposta para implementação de Sistema de Gestão Integrada de Meio Ambiente, Saúde e Segurança do Trabalho em Empresas de Pequeno e Médio Porte: Um Estudo de Caso da Indústria Metal-Mecânica. 2005. Tese - Universidade Federal do Rio de Janeiro, COPPE. Rio de Janeiro.

CUSIN, M. et al. Controle dos Custos da Qualidade. In: $1^{\circ}$ Simpósio Científico FTSG de Graduação e Pós-Graduação, 1, 2011. Caxias do Sul - RS. Disponível em:

<http://ojs.ftsg.edu.br/index.php/1simp/article/view/45/44>. Acesso em: 17 mar.2013.

ECKERT, A.; BIASIO, R.; MECCA, M. S.; ROLOFF, S. Custo da ociosidade na indústria calçadista: cálculo e análise em uma empresa do nordeste brasileiro. Exacta Engenharia da Produção, v.11, n. 2, 2013. Disponível em:

<http://www4.uninove.br/ojs/index.php/exacta/article/view/4208>. Acesso em: 05 Fev. 2014.

ECKERT, A. Teoria da Contabilidade para o Exame de Suficiência do CFC. 2.ed. São Paulo: Edipro, 2013.

FERREIRA, J. Â. Custos Industriais: Uma ênfase gerencial. São Paulo: Editora STS, 2007. Disponível em: <http://books.google.com/books?id=c-OvJl1OgfEC\&dq=pt-PT>. Acesso em: 8 out. 2012.

FERREIRA, J. B.; MEDEIROS, T. U.. Gerenciamento dos Custos da Qualidade e Competitividade. In: XXVII Encontro Nacional de Engenharia de Produção, 27, 2007, Foz do Iguaçu - PR. Anais eletrônicos: Foz do Iguaçu, 2007. Disponível em: <http://www. abepro.org.br/biblioteca/ENEGEP2007_TR580443_9814.pdf>. Acesso em: 29 set. 2012.

FONS, L. A. S. Integration of quality cost and accounting practices. The TQM Journal. v. 24, n. 4, p.338 - 351. 2012. Disponível em: <http://dx.doi.org/10.1108/ 17542731211247364>. Acesso em: 9 out. 2012.

HANSEN, D. R.; MOWEN, M. M. Gestão de custos: contabilidade e controle. São Paulo: Thomson, 2001.

LINS, B. E. Custo da qualidade. In: Cadernos Aslegis 5 (14): 45-49. 2001. Disponível em: <http://www.aslegis.org.br/aslegisoriginal/images/stories/cadernos/2001/ Caderno14/Custo_da_qualidade.pdf >. Acesso em: 2 nov. 2012.

MAHER, M. Contabilidade de custos: criando valor para a administração. São Paulo: Atlas, 2001. 
MARTINS, E. Contabilidade de custos. 9.ed. São Paulo: Atlas, 2003.

OLIVEIRA, L. H. O Princípio 80/20 "Segredo para se Obter Mais com Menos". ([200-?]) Centro Universitário das Faculdades Associadas de Ensino FAE São João da Boa Vista - UNIFAE. Disponível em: <http://admunifaeluciel.wikispaces.com/file/view/ PARETO++Princ\%C3\%ADpio+80-20.pdf>. Acesso em: 19 mai.2013.

OLIVEIRA, S. E.; ALLORA, V.; SAKAMOTO, F. T. C. Utilização conjunta do método UP' (Unidade de produção - UEP') com o Diagrama de Pareto para identificar as oportunidades de melhoria dos processos de fabricação: um estudo na agroindústria de abate de frango. In: Custos e @ gronegócio online - v. 2 - n. 2 - Jul/Dez 2006. ISSN: 1808-2882 - Disponível em: <http://www.custoseagronegocioonline.com.br/numero2v2/Diagrama\%20de\%20pareto.pdf >. Acesso em: 28 abr.2013.

PINTO, L. J. S.; GOMES, J. S. Gerenciamento de Custos que não agregam valor: Evidências geradas nos relatórios dos custos da qualidade de uma indústria brasileira. In: XVII Congreso de La Asociación Espanõla de Contabilidad y Administración de Empresas, 12, 2011, Universidad de Granada - Espanha. Disponível em:

<http://www.professores.uff.br/leonardopinto/images/stories/artigo_gerenciamento\%20de\%20custo s\%20que\%20no\%20agregam\%20valor_aeca.pdf>. Acesso em: 10 de mar.2013.

PINTO, L. J. S.; GOMES, J. S. Apuração e controle dos custos da qualidade: um estudo de caso. In: XVII Congresso Brasileiro de Custos, 17, 2010. Belo Horizonte - MG. Disponível em: <http://www.abcustos.org.br/texto/viewpublic?ID_TEXTO =3103>. Acesso em: 09 de mar. 2013.

PORTON, R. A. B.; GOULART, F. Custos da qualidade em uma indústria de plásticos flexíveis. In: XVI Congresso Brasileiro de Custos, 16, 2009. Fortaleza - CE. Disponível em: <http://www.abcustos.org.br/texto/viewpublic?ID_TEXTO=2916>. Acesso em: 11 de mar.2013.

ROBLES JR, A. Custos da qualidade: aspectos econômicos da gestão da qualidade e da gestão ambiental. 2.ed. revisada e ampliada. São Paulo: Atlas, 2003.

SÁ, V. M. R. Custo da Qualidade nas Indústrias de Transformação de Pernambuco.

Dissertação de Mestrado. Universidade Federal de Pernambuco. 2003. Recife. Disponível em: < http://www.liber.ufpe.br/teses/arquivo/20040707154528.pdf>. Acesso em: 8 out.2012.

SATO, S. A. S. S.; ALMEIDA, W. A. L. Custo da Qualidade: Conceitos a mensuração - um caso de sucesso da montadora Fiat no Brasil. In: XIV Congresso Brasileiro de Custos, 14, 2007. João Pessoa - PB. Disponível em: < http://www.abcustos.org.br/texto/viewpublic?ID_TEXTO=2377>. Acesso em: 13 abr.2013.

SIMECS - Sindicado das Indústrias Metalúrgicas, Mecânicas e de Material Elétrico de Caxias do Sul. Indústria Metalmecânica: perda de competitividade e ameaça de desindustrialização impulsionam desempenho negativo em 2011. Caxias do Sul - RS - Informativo. Disponível em: <http://www.simecs.com.br/noticias-e-informativo/informativo.asp>. Acesso em: 13 abr. 2013.

TAUFFER, R. L.Termo de Referência para elaboração de Planos de Gerenciamento de Resíduos Sólidos Industriais para Empresas do Ramo Metal Mecânico no Município de Caxias do Sul - RS. 2010. 91 f. Monografia. Universidade de Passo Fundo. Disponível em: <http://usuarios.upf.br/ engeamb/TCCs/2010-2/RENATO\%20TAUFFER.pdf >. Acesso em: 13 abr. 2013. 
YIN, R.K. Estudo de caso: planejamento e métodos. 3. ed. Porto Alegre: Bookman, 2005.

\section{Dados dos autores}

\section{Nome completo: Alex Eckert}

Filiação institucional: Universidade de Caxias do Sul - UCS

Departamento: Centro de Ciências Sociais - CCSO

Função ou cargo ocupado: Professor do Curso de Ciências Contábeis

Endereço completo para correspondência (bairro, cidade, estado, país e CEP): Telefones para contato: Rua Francisco Getúlio Vargas, 1130 - Bloco J, CEP 95.070-560, Caxias do Sul, RS Telefone: (54) 3218-2267

e-mail: aeckert@ucs.br

Nome completo: Marlei Salete Mecca

Filiação institucional: Universidade de Caxias do Sul - UCS

Departamento: Centro de Ciências Sociais - CCSO

Função ou cargo ocupado: Professora do Curso de Ciências Contábeis e do Programa de Pós

Graduação em Turismo

Endereço completo para correspondência (bairro, cidade, estado, país e CEP): Telefones para contato: Rua Francisco Getúlio Vargas, 1130 - Bloco J, CEP 95.070-560, Caxias do Sul, RS Telefone: (54) 3218-2267

e-mail:msmecca@ucs.br

\section{Nome completo: Roberto Biasio}

Filiação institucional: Universidade de Caxias do Sul - UCS

Departamento: Centro de Ciências Sociais - CCSO

Função ou cargo ocupado: Professor do Curso de Ciências Contábeis

Endereço completo para correspondência (bairro, cidade, estado, país e CEP): Telefones para contato: Rua Francisco Getúlio Vargas, 1130 - Bloco J, CEP 95.070-560, Caxias do Sul, RS Telefone: (54) 3218-2267

e-mail:rbiasio@ucs.br

\section{Nome completo: Andressa Basso}

Filiação institucional: Universidade de Caxias do Sul - UCS

Departamento: Centro de Ciências Sociais - CCSO

Função ou cargo ocupado: Bacharel em Ciências Contábeis 
Endereço completo para correspondência (bairro, cidade, estado, país e CEP): Telefones para contato: Rua Francisco Getúlio Vargas, 1130 - Bloco J, CEP 95.070-560, Caxias do Sul, RS Telefone: (54) 3218-2267

e-mail:dessinhabasso@hotmail.com

Submetido em: 05/02/2014

Aceito em: 17/12/2014 